\title{
Prevalence of Salmonella spp. in Pigs, Chickens and Ducks in the Mekong Delta, Vietnam
}

\author{
TRAN Thi Phan ${ }^{1}$, LY Thi Lien Khai ${ }^{1}$, NGUYEN Thu Tan ${ }^{1)}$, Masato AKIBA ${ }^{2)}$, Natsue OGASAWARA ${ }^{3)}$, \\ David SHINODA ${ }^{3)}$, Alexandre Tomomitsu OKATANI ${ }^{3)}$ and Hideki HAYASHIDANI ${ }^{3) *}$ \\ ${ }^{1)}$ Department of Veterinary Medicine, College of Agriculture, Campus II, Cantho University, 3/2 St., Cantho, Vietnam, ${ }^{2)}$ National Institute \\ of Animal Health, 3-1-5 Kannondai, Tsukuba, Ibaraki 305-0856 and ${ }^{3)}$ Department of Veterinary Medicine, Faculty of Agriculture, Tokyo \\ University of Agriculture and Technology, 3-5-8 Saiwai-cho, Fuchu, Tokyo 183-8509, Japan
}

(Received 26 November 2003/Accepted 23 March 2004)

ABSTRACT. In order to determine the prevalence of Salmonella spp. in domestic animals in 6 provinces of the Mekong Delta, Vietnam, 1,098 fecal or intestinal content samples from pigs, chickens, and ducks were examined in the period from July to October, 2000. Salmonella spp. were isolated from $78(7.1 \%)$ of the total samples, which included $23(5.2 \%)$ of 439 pigs, 24 (7.9\%) of 302 chickens, and $31(8.7 \%)$ of 357 ducks. From those samples, 80 Salmonella strains were isolated and 25 serovars were identified. The predominant serovars were $S$. Javiana, $S$. Derby, and $S$. Weltevreden. $S$. Javiana and $S$. Weltevreden were detected together in pigs, chickens, and ducks. These results indicate that the serovars of Salmonella are widely distributed in domestic animals in the Mekong Delta, Vietnam. KEY WORDS: domestic animal, Salmonella,Vietnam.

J. Vet. Med.Sci. 66(8): 1011-1014, 2004

Salmonella is recognized worldwide as an important foodborne human pathogen, and is found in the intestinal tract of both animals and humans [8]. Animals that carry Salmonella play an important role in the spread of salmonellosis [16]. In the past decade, the incidence of systemic infection of typhoid Salmonella has declined markedly all over the world including Japan, but food poisoning caused by other Salmonella serovars such as Enteritidis has increased [8, 14], and meat from domestic animals (pigs, chickens, and ducks) has been reported to be the major cause of foodborne disease of Salmonella [16].

The Mekong Delta consisting of 12 provinces is located in the southern area of Vietnam, and 3 millions pigs and 44 million poultry were raised in this area in 2000 . However, few reports have been published regarding the prevalence of Salmonella spp. in domestic animals in the Mekong Delta, although there have been some case reports regarding Salmonella Typhi in Vietnam [6, 17]. The present study was therefore conducted in order to determine the prevalence of Salmonella in pigs, chickens, and ducks in the Mekong Delta, Vietnam.

During the period from July to October 2000, 1,098 fecal or intestinal content samples from pigs, chicken and ducks in 6 provinces of the Mekong Delta were examined for the prevalence of Salmonella spp. A total of 439 fecal samples were taken from 2- to 4- month-old pigs kept in 47 smallscale farms and 5 commercial farms. The small-scale farms raised only a few pigs which were kept inside simple pens and were mostly given leftovers from the household and water from nearby rivers or ponds. In the commercial farms, the pigs were caged and were given commercially

\footnotetext{
* Correspondence to: Hayashidani, H., Laboratory of Animal Hygiene, Department of Veterinary Medicine, Faculty of Agriculture, Tokyo University of Agriculture and Technology, 3-5-8 Saiwai-cho, Fuchu, Tokyo 183-8509, Japan.
}

produced food and disinfected tap water. A total of 302 samples of adult chickens from 27 slaughter houses were also analyzed. The chicken came from both small-scale and commercial farms and their habitat was similar to those of the pigs. Cecal samples of 357 adult ducks were also collected. Only a few samples of ducks came from commercial farms which produced mainly ducklings for sale to smallscale farms. In small-scale farms, the ducklings fed on snails, insects, etc. in the rice fields. After the rice had been harvested, the grown ducks fed on the leftover rice.

The samples from the pigs were taken as rectum swabs or fresh feces. The swabs were put in Carry-Blair transport medium (Nissui, Tokyo, Japan), and the samples of the feces placed in sterile plastic bags. All samples were cooled in an icebox and immediately transported to Cantho University in Vietnam for examination. The intestines of the ducks and chickens were collected aseptically in the slaughterhouses after evisceration. All samples were put into sterile plastic bags, cooled, and brought to the laboratory where cecal samples were taken aseptically.

In the laboratory, one gram of each fecal sample or a swab were put aseptically into a tube containing $9 \mathrm{~m} l$ EEM broth (Eiken, Tokyo, Japan) for pre-enrichment and incubated at $37^{\circ} \mathrm{C}$ for $24 \mathrm{hr}$. Then $1 \mathrm{ml}$ of the pre-enrichment broth in each tube was transferred to $9 \mathrm{~m} l$ Hajna tetrathionate broth (Eiken) and further incubated at $37^{\circ} \mathrm{C}$ for $24 \mathrm{hr}$. One loopful of each enrichment was inoculated onto a plate with brilliant green agar (BGA; Oxoid, Hampshire, UK) and mannitol lysine crystal violet brilliant green agar (MLCB, Nissui). The plates were incubated at $37^{\circ} \mathrm{C}$ for $24 \mathrm{hr}$. Colonies morphologically similar to those of Salmonella spp. were subcultured for biochemical examination. Biochemical characteristics were examined using triple-sugar iron agar (Eiken), VP medium (Eiken), and lysine indol motility medium (Eiken). When typical Salmonella reactions were 
Table 1. Prevalence of Salmonella spp. in domestic animals in the Mekong Delta, Vietnam

\begin{tabular}{clcrl}
\hline \multirow{2}{*}{ Animal } & Type of farm & $\begin{array}{c}\text { No. of samples } \\
\text { examined }\end{array}$ & $\begin{array}{c}\text { No. of Salmonella } \\
\text { positive animals (\%) }\end{array}$ \\
\hline \multirow{2}{*}{ Pig } & Industrial farms & 220 & 5 & $(2.3)^{\mathrm{a})}$ \\
& Small scale farms & 219 & 18 & $(8.2)$ \\
& Total & 439 & 23 & $(5.2)$ \\
\multirow{5}{*}{ Dhicken } & Industrial farms & 192 & 12 & $(6.3)$ \\
& Small scale farms & 110 & $12(10.9)$ \\
& Total & 302 & 24 & $(7.9)$ \\
& Industrial farms & 36 & 3 & $(8.3)$ \\
& Small scale farms & 321 & 28 & $(8.7)$ \\
& Total & 357 & 31 & $(8.7)$ \\
& Grand Total & 1.098 & 78 & $(7.1)$ \\
\hline
\end{tabular}

a) Small scale farms $>$ Industrial farms $(p<0.01)$.

seen, additional biochemical tests were performed as described by Barrow and Feltham [3]. Serotyping of Salmonella isolates was accomplished with commercial $\mathrm{O}$ and $\mathrm{H}$ antisera (Denka Seiken, Tokyo, Japan) according to the method of Popoff and Le Minor [19].

In this study, relatively high percentages of Salmonella were detected in the three domestic animals examined. The percentage of Salmonella- positive samples from the different animals ranged from $5.2 \%$ in pigs to $8.7 \%$ in ducks (Table 1). The positive rate was significantly higher if the pigs had been raised in small-scale farms than in commercial farms. However, for chicken and ducks no significant difference was observed in the isolation rate of Salmonella between small-scale and commercial farms. In the positive samples, 80 Salmonella strains were isolated and 25 serovars were identified (Table 2). The predominant serovars in pigs were $S$. Javiana, $S$. Derby, and $S$. Weltevreden, in chickens $S$. Emek, $S$. Javiana, and $S$. Typhimurium, and in ducks $S$. Typhimurium and $S$. Weltevreden, with $S$. Javiana and $S$. Weltevreden being isolated in pigs, chickens, and ducks (Table 2).

The higher prevalence of Salmonella in pigs in the smallscale farms than in the commercial farms may be due to differences in the feed and the water. The pigs in the smallscale farms usually have been able to contact with other animals such as insects, birds, and rats which may be carriers of Salmonella. The Salmonella-positive rate of pigs from commercial farms, however, was almost the same as for pigs from developed countries such as Canada, 3.7\% (7/ 187) [10], Germany, 3.7\% (445/11,930) [13], and Japan, $2.3 \%$ (58/2,511) [12]. The most frequent Salmonella serovars from pigs reported in European countries and the U.S.A. are $S$. Typhimurium and $S$. Derby $[7,9,10]$. In Japan, according to Hiratsuka et al. [11], the same serovars such as $S$. Derby (22.4\%), S. Typhimurium (20.7\%), $S$. Infantis $(19.0 \%)$, and $S$. London $(13.8 \%)$ were reported to be dominant in pigs. In the present study, the dominant serovars of the pig isolates were $S$. Javiana (9/25), $S$. Derby $(4 / 25)$ and $S$. Weltevreden (3/25). No $S$. Typhimurium was detected.

Salmonella contamination in poultry is a worldwide prob-
Table 2. Serovars of Salmonella spp. isolates by animal

\begin{tabular}{|c|c|c|c|c|}
\hline \multirow{2}{*}{ Serotype } & \multicolumn{4}{|c|}{ No. of isolates } \\
\hline & Pig & Chicken & Duck & Total (\%) \\
\hline$S$. Aberdeen & 1 & & & $1 \quad(1.3)$ \\
\hline$S$. Anatum & & 1 & & $1 \quad(1.3)$ \\
\hline$S$. Braenderup & & & 1 & $1 \quad(1.3)$ \\
\hline$S$. Bovismorbificans & & & 2 & $2 \quad(2.5)$ \\
\hline$S$. Derby & 4 & & 1 & $5 \quad(6.3)$ \\
\hline S. Dublin & & & 1 & $1 \quad(1.3)$ \\
\hline S. Emek & & 8 & & $8(10.0)$ \\
\hline S. Enteritidis & & 1 & & $1 \quad(1.3)$ \\
\hline S. Hadar & 1 & & 1 & $2 \quad(2.5)$ \\
\hline$S$. Heibron & 1 & & & $1 \quad(1.3)$ \\
\hline S. Javiana & 9 & 5 & 3 & $17(21.3)$ \\
\hline$S$. Lexington & & & 3 & $3 \quad(3.8)$ \\
\hline$S$. Lome & & & 1 & $1 \quad(1.3)$ \\
\hline$S$. London & 1 & & & $1 \quad(1.3)$ \\
\hline$S$. Newport & & & 1 & $1 \quad(1.3)$ \\
\hline$S$. Senftenberg & & & 3 & $3 \quad(3.8)$ \\
\hline S. Singapore & 1 & & & $1 \quad(1.3)$ \\
\hline$S$. Southampton & & 1 & & $1 \quad(1.3)$ \\
\hline S. Stanley & & & 1 & $1 \quad(1.3)$ \\
\hline S. Tennessee & 1 & & & $1 \quad(1.3)$ \\
\hline$S$. Typhimurium & & 4 & 6 & $10(12.5)$ \\
\hline$S$. Tyresoe & & 1 & & $1 \quad(1.3)$ \\
\hline$S$. Wirchow & 1 & & & $1 \quad(1.3)$ \\
\hline$S$. Wagenia & & & 1 & $1 \quad(1.3)$ \\
\hline$S$. Weltevreden & 3 & 3 & 4 & $10(12.5)$ \\
\hline Untyped & 2 & 1 & 1 & $4 \quad(5.0)$ \\
\hline Total & 25 & 25 & 30 & $80 \quad(100)$ \\
\hline
\end{tabular}

lem [18]. In Japan, Limawongpranee et al. [15] reported that Salmonella was isolated from $14.3 \%(336 / 2,345)$ of the cecal contents of broiler chickens in commercial farms and the predominant Salmonella serovars were $S$. Blockley, $S$. Hadar, and $S$. Bredeney. Akiba et al. [1] also reported that the most common Salmonella serovars from chickens in Japan in the period from 1980 to 1995 were $S$. Agona, $S$. Hadar, and $S$. Enteritidis, in that order. In Thailand, Boonmar et al. [4] reported that Salmonella was isolated from $6.7 \%(19 / 285)$ of the feces of broiler chickens and the predominant Salmonella serovar was $S$. Enteritidis. In Malaysia, Salmonella was isolated from $14.3 \%$ (14/98) of 
intestinal samples of broilers and 35.5\% (158/445) of broiler carcasses [22]. The predominant serovars were $S$. Enteritidis, $S$. Muenchen, and $S$. Kentucky. The Salmonella-positive rate of chickens from commercial farms in Vietnam was not significantly high relative to other countries such as Japan, Thailand, and Malaysia. Although S. Enteritidis has become the predominant serovar worldwide $[18,21]$, in the present study only one strain of $S$. Enteritidis was isolated from chicken. However, since $S$. Enteritidis is the predominant serovar in the neighboring countries, Thailand and Malaysia [2], it may spread widely in Vietnam in the future.

Ducks are the one of the more important domestic food stock animals in Vietnam. Few reports regarding the prevalence of Salmonella in ducks have been published. Price et al. [20] reported that 457 (93\%) of 491 Salmonella strains originating from ducks in the U.S.A. were $S$. Typhimurium. The predominant Salmonella serovar from ducks in Slovenia was $S$. Typhimurium (61\%), but $S$. Anatum (22\%) and S.Meleagridis (4\%) were also found [24]. Saitanu et al. [23] reported that the predominant Salmonella serovar in duck eggs in Thailand were $S$. Typhimurium(23.3\%), $S$. Cerro(17.7\%), and $S$. Tennessee(12.0\%). In the present study, the predominant serovar from ducks in Vietnam was also $S$. Typhimurium. Therefore, ducks seem to be sensitive to $S$. Typhimurium. $S$. Typhimurium was also found in water samples from ponds and waterways in Vietnam as found in Cantho province by Tran et al. [25]. The serovar in ducks may have been brought from European countries because many ducks have been imported from the countries to the Mekong Delta.

$S$. Javiana and $S$. Weltevreden were isolated together in pigs, chicken and ducks. Both serovars are rare in developed countries but are sometimes detected in Southeast Asian countries such as Thailand and Malaysia [2, 5, 26]. However, a major outbreak of human Salmonella infection due to $S$. Javiana has been reported in the USA [11]. $S$. Weltevreden has been reported to be a major cause of human Salmonellosis in Thailand [4] and Malaysia [26]. Since, as far as we know, no studies have been published regarding the prevalence of Salmonella serovars in Vietnam, the above serovars may be widely distributed in nature and may cause foodborne diseases in this country.

In the present study, Salmonella was isolated at a relatively high rate from domestic animals such as pigs, chickens and ducks in 6 provinces in the Mekong Delta, Vietnam. These results indicate that Salmonella, especially $S$. Javiana and $S$. Weltevreden, may be widely distributed in domestic animals and these animals may play an important role as a reservoir of Salmonella in the Mekong Delta. In order to learn more about the implications of this situation in regard to animal and public health, further surveys should be carried out to examine the contamination of Salmonella in foods of animal origin and the antimicrobial resistance of the Salmonella isolates in Vietnam.

ACKNOWLEDGEMENT. The authors wish to thank Japan International Cooperation Agency (JICA) for funding this study and Dr. Hilde Nissen (Norway) for revising the manuscript.

\section{REFERENCES}

1. Akiba, M., Ohya,T., Mitsumori, M., Sameshima, T. and Nakazawa, M. 1996. Bull. Natl. Inst. Anim. Health 102: 103: 43-48 (in Japanese).

2. Arumugaswamy, K., Rusel, G., Abdul Hamid, S.N. and Cheah, C.T. 1995. Food Microbiol. 12: 3-8.

3. Barrow, G.I. and Feltham, R.K.A. 1993. Cowan and Steel's Manual for the Identification of Medical Bacteria. 3rd ed., Cambridge University Press, Great Britain.

4. Boonmar, S., Bangtrakulnonth, A., Pornrunangwong, S., Marnrin, N., Kaneko, K. and Ogawa, M. 1998a. J. Vet. Med. Sci. 60: $877-880$.

5. Boonmar, S., Bangtrakulnonth, A., Pornrunangwong, S., Marnrin, N., Kaneko, K. and Ogawa, M. 1998b. J. Vet. Med. Sci. 60: 1233- 1236 .

6. Connerton, P., Wain, J., Hien, T.T., Ali, T., Parry, C., Chinh, N.T., Vinh, H., Ho, V.A., Diep, T.S., Day, N.P., White, N.J., Dougan, G. and Farrar, J.J. 2000. J. Clin. Microbiol. 38: 895897.

7. Currier, M., Singleton, M.J., Lee. J. and Lee, D.R. 1986. J. Food Protect. 49: 366-368.

8. Doyle, M.P. and Cliver, D.O. 1990. pp. 186-204. In: Foodborne Diseases (Doyle, M.P. ed.), Academic Press, New York, U.S.A.

9. Fedorka-Cray, P.J., Gray, J.T. and Wray, C. 2000. pp. 191207. In: Salmonella in Domestic Animals (Wray, C. and Wray, A. eds.), CABI Publishing, Oxon, Great Britain.

10. Finlay, R.C., Mann, E.D. and Horning, J.L. 1986. Can. Vet. J. 27: $185-187$.

11. Hedberg, C.W., Koriath, J.A., D'Aoust, J.Y., White,K.E., Schell, W.L., Miller, M.R., Cameron, D.N., MacDonald, K.L. and Osterhorm, M.T. 1992. J. Am. Med. Assoc. 268: $3203-$ 3207.

12. Hiratsuka, S., Kamibeppu, M., Hirosawa, T., Futagawa, K. and Fukuyasu, T. 2000. J. Jpn.Vet. Med. Assoc. 53: 533-536 (in Japanese).

13. Käsbohrer, A., Protz, D., Helmuth, R., Nöckler, K., Blaha, T., Conraths, F.J. and Geue, L. 2000. Eur. J. Epidemiol. 16: 141146.

14. Kudoh, Y. 1997. Rinsyo byori 45: 242-248 (in Japanese).

15. Limawongpranee, S., Hayashidani, H., Okatani, A.,T., Ono, K., Hirota, C., Kaneko, K. and Ogawa, M. 1999. J. Vet. Med. Sci. 61: 255-259.

16. Nisbet, D.V. and Ziprin, L. 2001. pp. 265-284. In: Foodborn Disease Handbook, vol.1 Bacterial Pathogen (Huy, Y., Pierson, M.D. and Gorham, J.R. eds.), Marcel Dekker, New York, U.S.A.

17. Nguyen, T.A., Ha Ba, K. and Nguyen, T.D. 1993. Bull. Soc. Patho. Exot. 86: 476-478.

18. Poppe, C. 2000. pp. 107-131. In: Salmonella in Domestic Animals (Wray ,C. and Wray, A. eds.), CABI Publishing, Oxon, Great Britain.

19. Popoff, M.Y. and Le Minor, L. 1997. Antigenic Formulas of the Salmonella Serovars. WHO Collaborating Centre for Reference and Research on Salmonella, Institute Pasteur, Paris, France.

20. Price, J.I., Dougherty, E. and Bruner, D.J.W. 1962. Avian Dis. 6: 145-147. 
21. Rodrique, D.C.,Tauxe, R.V. and Rowe, B. 1990. Epidemiol. Infect. 105: 21-27.

22. Rusel, G., Khair,J.,Radu, S., Cheah, C.T. and Yassin, R.M. 1996. Int. J. Food Microbiol. 33: 183-194.

23. Saitanu, K., Jerngklinchan, J. and Koowatananukul, C. 1994. Southeast Asian J. Trop. Med. Public Health 25: 328-331.
24. Simco, S. 1988. Imunoprofylaxia 1-2: 92-101.

25. Tran, T.P., Ly, T.L.K., Hayashidani, H., Akiba, M., Watanabe, T., Taniguchi, T. and Chau, B.L. 2002. JIRCAS Working Report 26: 21-24.

26. Yasin, R., Jegathesan, M. and Tiew, C.C. 1996. Asia Pac. J. Pub. Health 9: 1-5. 